\title{
Vulnerabilidade à degradação dos solos da Bacia do Acaraú, Ceará1
}

\author{
Vulnerability to soil degradation in the Acaraú Basin, State of Ceara
}

\author{
Lydia Helena da Silva de Oliveira Mota ${ }^{2 *}$ e Gustavo Souza Valladares ${ }^{3}$
}

\begin{abstract}
Resumo - Este trabalho objetivou elaborar um mapa de vulnerabilidade à degradação dos solos da bacia do rio Acaraú, CE, através de Sistema de Informações Geográficas e de metodologia multicritério aditivo. Para a obtenção das classes de vulnerabilidade, foram avaliados os temas geologia, geomorfologia, pedologia, vegetação e clima, definindo-se cinco classes: estável, moderadamente estável, medianamente estável/vulnerável, moderadamente vulnerável e vulnerável. A classe medianamente estável/vulnerável foi a mais representativa, ocupando $9.776 \mathrm{~km}^{2}$ de extensão $(67,8 \%$ da bacia), seguida da classe moderadamente estável que ocupou $4.180 \mathrm{~km}^{2}$ de extensão (mais de $28 \%$ da bacia). Os resultados obtidos mostraram a viabilidade da aplicação do método para a elaboração do mapa de vulnerabilidade ambiental que pode ser utilizado na gestão territorial da bacia do Rio Acaraú.
\end{abstract}

Palavras-chave - Risco ambiental. Sistema de Informações Gegoráficas. Gestão agro-ambiental.

\begin{abstract}
This work aimed to prepare a map of soil degradation vulnerability in the Acaraú basin, Ceará, through the Geographic Information System and multicriterium additive methodology. For the obtaining of classes of vulnerability, we evaluated information related to geology, geomorphology, pedology, vegetation and climate, resulting in five classes: stable, moderately stable, medium stable/vulnerable, moderately vulnerable and vulnerable. The class medium stable/vulnerable was the most representative, occupying $9,776 \mathrm{~km}^{2}$ of extension $(67.8 \%$ of the basin), followed by the class moderately stable, which occupied $4,180 \mathrm{~km}^{2}$ of extension (more than $28 \%$ of the basin). The results showed the viability of the method for preparing the map of environmental vulnerability, which can be applied in the territorial management of the Acaraú basin.
\end{abstract}

Key words - Environmental risk. Geographic Information System. Environmental management.

\footnotetext{
* Autor para correspondência

${ }^{1}$ Recebido para publicação em 26/03/2010; aprovado em 03/02/2011

Pesquisa financiada pelo CNPq, processo 471433/2009-8

${ }^{2}$ Bolsista da CAPES, Programa de Pós-Graduação em Agronomia: Solos e Nutrição de Plantas, Departamento de Ciências do Solo/UFC, Fortaleza-

CE, Brasil, lydiaufc@hotmail.com

${ }^{3}$ Departamento de Ciências do Solo, CCA/UFC, Fortaleza-CE, Brasil, valladares@ufc.br
} 


\section{Introdução}

As atividades antrópicas têm gerado degradação ambiental, incluindo erosão e contaminação de solos, sedimentos e corpos d'água. O modelo impactante atualmente adotado coloca em risco a sustentabilidade dos sistemas produtivos. Assim, os impactos ambientais negativos mostram a despreocupação humana com a sobrevivência das futuras gerações (SUCUPIRA, 2006).

A bacia hidrográfica é considerada a unidade espacial de planejamento mais apropriada, pois permite a integração multidisciplinar entre distintos sistemas de planejamento e gerenciamento, estudo e atividade ambiental, possibilitando, assim, o controle objetivo dos recursos naturais e socioeconômicos, favorecendo a integração de práticas de uso e manejo do solo, da água e a organização comunitária (NASCIMENTO; VILLAÇA, 2008). Nesse sentido, diversos estudos têm sido realizados na bacia do Rio Acaraú, mostrando a importância dessa unidade de estudo para análises agroambientais (ANDRADE et al., 2006; BATISTA et al., 2006; MEIRELES et al., 2007).

Segundo Mafra (1997), deve ser incorporado ao planejamento do uso do solo, o estudo da erosão, incluindo os fatores relacionados à atuação dos processos erosivos e à detecção das áreas mais susceptíveis (atual e potencial), com o objetivo de regular as ações sobre as mesmas, buscando uma incidência mínima de uso para evitar os prejuízos sobre as atividades humanas e sobre o meio ambiente.

A ocupação humana em áreas consideradas vulneráveis sob o ponto de vista agrícola tem aumentado o processo de perda do solo, o qual ocorre naturalmente devido à associação do clima com os tipos de litologia, relevo, solo e cobertura vegetal (SPÖRL; ROSS, 2004; GOMES, 2005). Para Mello et al. (2006), a falta de planejamento do uso do solo pode levar a processos erosivos em intensidade e velocidade que ultrapassam os limites de tolerância. Tendo em vista que a degradação dos solos afeta a sustentabilidade do agroecossistema inteiro (NAVAS et al., 2005), as práticas de conservação do solo e os métodos de avaliação de impactos ambientais e de perdas de solo surgem como importantes ferramentas no planejamento agroambiental.

Nos últimos anos, analisando-se o meio físico e biótico, foram realizados trabalhos baseados no conceito de ecodinâmica (TRICART, 1977), com o intuito de desenvolver uma metodologia para a geração de cartas que dividam uma região em classes de maior ou menor vulnerabilidade aos processos de degradação do solo, utilizando, para isso, dados de geologia, geomorfologia, pedologia, fitogeografia e clima (CREPANI et al., 2001). Para o tratamento e cruzamento dessas informações, é utilizado um sistema integrado, composto por bancos de dados e sistema de informação geográfica (SIG) que otimizam e permitem o acesso e consultas sobre o produto gerado. Com essas técnicas, trabalhos que visam mapear riscos ambientais têm sido produzidos para diferentes áreas do Nordeste brasileiro (BATISTELLA; VALLADARES, 2009; VALLADARES; FARIA, 2004).

O objetivo do presente trabalho foi gerar um mapa de vulnerabilidade à degradação dos solos da bacia do Rio Acaraú, utilizando-se a metodologia multicritério aditivo, com o intuito de fornecer uma base sintética adequada para a tomada de decisão e a gestão territorial.

\section{Material e métodos}

A bacia do Rio Acaraú está situada na região norte do Estado do Ceará. Essa região é drenada exclusivamente pelo rio Acaraú e seus afluentes (FIG. 1), ocupando uma área da ordem de $14.416 \mathrm{~km}^{2}$, o que representa $9,73 \%$ da área do Estado do Ceará. Segundo Araújo e Freire (2007), esta bacia banha aproximadamente vinte e cinco municípios cearenses e é considerada a segunda maior do Ceará. O rio Acaraú nasce na serra das matas em cotas superiores a $800 \mathrm{~m}$ e os principais afluentes encontram-se na margem direita: os rios dos Macacos, Groiaíras, Jacurutu e Sabonete. Na margem esquerda, o afluente de maior destaque é o rio Jaibara. A bacia do Acaraú possui aproximadamente $315 \mathrm{~km}$ de extensão e desenvolve-se no sentido sul-norte (COGERH, 2009).

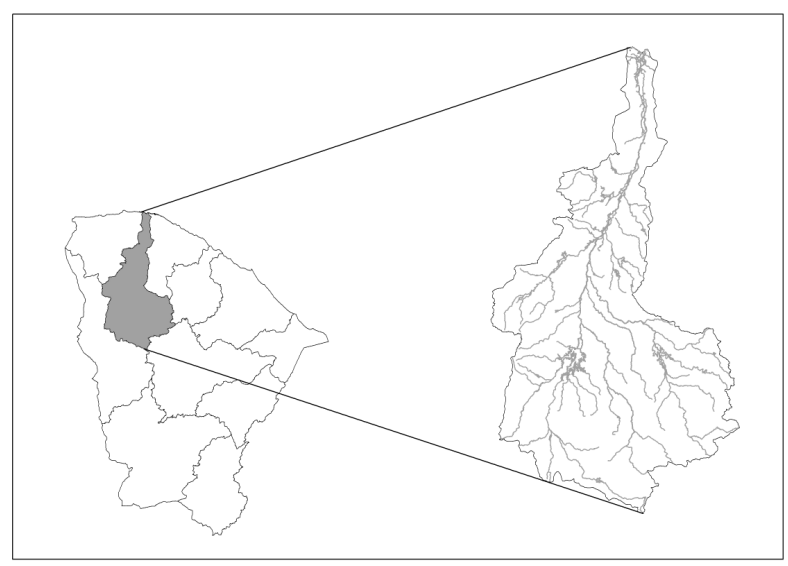

Figura 1 - Bacia do Rio Acaraú, com a rede de drenagem 
A bacia do Rio Acaraú apresenta geomorfologia com forte declividade no seu trecho bem inicial, por ser uma região montanhosa. A declividade reduz bastante no primeiro terço, predominando o relevo suave que caracteriza a bacia (SOBRINHO, 2006). Tem a ocorrência de um cordão de significativa elevação ao longo de quase todo o seu comprimento, principalmente onde se encontra a chapada do Araripe (face sudoeste). Outra importante região montanhosa situa-se na parte central da face noroeste, a serra da Meruoca, de amplitude mais localizada (NASCIMENTO, 2008).

Segundo a classificação de Köppen, a parte alta da bacia do Acaraú possui clima do tipo BSw'h' (semi-árido quente) com chuvas de verão a outono e temperaturas médias mensais maiores que $18{ }^{\circ} \mathrm{C}$. $\mathrm{Na}$ parte baixa da bacia é Aw' (tropical chuvoso) com chuvas máximas no outono. A umidade relativa média varia de níveis $<50 \%$ a $>80 \%$, onde o primeiro ocorre nas regiões mais secas e nos meses de estiagem e a segunda ocorre nas regiões mais úmidas (KÖPPEN; GEIGER, 1928).

A geologia da bacia do Acaraú encontra-se constituída pelo embasamento cristalino formado principalmente por rochas ígneas e metamórficas, como os granitos, migmatitos, paragnaisses e ortognaisses, os quais correspondem a aproximadamente $90 \%$ da bacia. O restante da bacia encontra-se no embasamento sedimentar do Grupo Barreiras (Terciário) e próximas aos rios (Quaternário). Os solos predominantes na bacia do Acaraú são Luvissolos e Neossolos Litólicos. A vegetação predominante da região é do tipo Caatinga arbórea e arbustiva (RADAMBRASIL, 1973).

Para a elaboração do mapa de vulnerabilidade natural à perda de solo na bacia do Acaraú, foram necessários os seguintes materiais: mapas dos temas pedologia e geologia do RADAMBRASIL, disponibilizados na forma digital pelo Serviço Geológico do Brasil (CPRM), mapas dos temas vegetação e clima do Instituto de Pesquisa e Estratégia Econômica do Ceará (IPECE), mapas do tema geomorfologia do Projeto RADAM, todos na escala de 1:1.000.000 das folhas SA.24 e SB.24/25 de Fortaleza e Jaguaribe, respectivamente (SAD-69 Zona 24S), e o modelo digital de elevação (MDE) da missão SRTM (NASA, 2009) como base para o tema declividade.

As atividades necessárias à transformação dos dados do formato analógico para formato digital e a respectiva inclusão no banco de dados geográficos incluiu: a digitalização da cartografia básica e das temáticas; a análise e correção dos mapas digitalizados; conversão para o formato digital de dados alfanuméricos; uniformização entre projeções cartográficas; interpretação dos diversos temas para vulnerabilidade; uniformização dos dados na base raster com $100 \mathrm{~m}$ de tamanho do pixel.
Para a determinação da vulnerabilidade dos solos, foram atribuídas notas de risco à degradação para cada um dos critérios: geomorfologia, pedologia, vegetação, geologia e clima, sendo então obtidos os mapas de vulnerabilidade referentes a cada variável.

A metodologia aplicada neste trabalho baseouse em Crepani et al. (2001) que consiste em apresentar um intervalo de valores de estabilidade/instabilidade (ou vulnerabilidade) distribuídos entre as situações de predomínio dos processos pedogenéticos (valores próximos de 1,0), passando por situações intermediárias (valores ao redor de 2,0) e situações de predomínio dos processos de morfogênese (valores próximos de 3,0) e recebe atribuições de valores conforme a Tabela 1 .

Tabela 1 - Classes de vulnerabilidade e/ou estabilidade à degradação

\begin{tabular}{cc}
\hline $\begin{array}{c}\text { Escala de } \\
\text { Vulnerabilidade }\end{array}$ & Grau de Vulnerabilidade \\
\hline 1,0 a 1,3 & Estável \\
1,4 a 1,7 & Moderadamente Estável \\
1,8 a 2,2 & Medianamente Estável/Vulnerável \\
2,3 a 2,6 & Moderadamente Vulnerável \\
2,7 a 3,0 & Vulnerável \\
\hline
\end{tabular}

Fonte: Modificada de Crepani et al., (2001)

O modelo foi aplicado individualmente aos temas citados anteriormente, de forma a atribuir valores de risco para que fossem analisados em conjunto com os mapas temáticos da área de estudo, gerados por meio do software ArcGIS com a função RASTER CALCULATOR, permitindo o tratamento dos dados e as análises da vulnerabilidade natural à perda de solos.

O valor final foi resultante da média aritmética dos valores individuais segundo uma equação empírica (Eq. 1) que busca representar a posição desta unidade dentro da escala de vulnerabilidade natural à perda de solo:

$\mathrm{V}=(\mathrm{G}+\mathrm{R}+\mathrm{S}+\mathrm{Ve}+\mathrm{C}) / 5$

Onde:

$\mathrm{V}=$ Vulnerabilidade; $\mathrm{G}=$ vulnerabilidade para $\mathrm{o}$ tema geologia; $\mathrm{R}=$ vulnerabilidade para $\mathrm{o}$ tema geomorfologia; $\mathrm{S}=$ vulnerabilidade para o tema pedologia; $\mathrm{Ve}=$ vulnerabilidade para o tema vegetação; $\mathrm{C}=$ vulnerabilidade para o tema clima.

A vulnerabilidade para o tema geologia apresenta os valores do grau de vulnerabilidade das unidades de mapeamento de litotipos (TAB. 2). 
Tabela 2 - Valores atribuídos às unidades litotipo de geologia, para a Bacia do Acaraú

\begin{tabular}{|c|c|}
\hline Litotipo & Valor \\
\hline Anfibóilio gnaisse e/ou anfibolitos & 1,8 \\
\hline Arcóseos e grauvacas & 2,6 \\
\hline Areias & 3,0 \\
\hline Arenitos e conglomerados & 2,5 \\
\hline Arenitos, folhelhos e siltitos & 2,7 \\
\hline Argilas, areias argilosas e cascalhos & 2,8 \\
\hline Basaltos, andesitos, riolitos & 1,5 \\
\hline Conglomerados e arenitos & 2,5 \\
\hline Granitos, migmatitos e paraderivadas & 1,2 \\
\hline Granitóides & 1,2 \\
\hline Granitóides cinzentos & 1,2 \\
\hline Granitóides diversos & 1,2 \\
\hline Granulitos máficos, enderbitos e leptinitos & 1,2 \\
\hline Metacalcários & 2,9 \\
\hline Metacalcários e margas & 2,9 \\
\hline Micaxistos & 1,7 \\
\hline Micaxistos, paragnaisses e quartzitos & 1,4 \\
\hline Monzonitos, granodioritos e sienitos & 1,3 \\
\hline Ortoconglomerados & 2,5 \\
\hline Ortognaisse facoidal milonítico & 1,3 \\
\hline Ortognaisses TTG e migmatitos & 1,3 \\
\hline Ortognaisses facoidais & 1,3 \\
\hline Paragnaisses e granitóides & 1,2 \\
\hline Paragnaisses, micaxistos e metacalcários & 1,6 \\
\hline Paragnaisses, ortognaisses, metabásicas e metacalcários & 1,4 \\
\hline Quartzitos & 1,0 \\
\hline Quartzitos e metarenitos & 1,0 \\
\hline Quartzitos, xistos e metavulcônicas & 1,3 \\
\hline Sedimentos argilo-arenosos & 3,0 \\
\hline Termometamorfitos & 1,7 \\
\hline
\end{tabular}

Fonte da litologia: RADAMBRASIL (1973)

Os temas pedologia e vegetação referem-se ao grau de vulnerabilidade das unidades de mapeamento de solos e de vegetação, respectivamente (TAB. 3 e 4).

Para estabelecer os valores de escala de vulnerabilidade para as unidades de paisagem natural ligadas à geomorfologia, foi necessário analisar, conforme a equação abaixo, os seguintes índices morfométricos do terreno: dissecação do relevo, amplitude altimétrica e declividade.
$\mathrm{Ge}=\left(\mathrm{G}^{\circ}+\mathrm{A}+\mathrm{D}\right) / 3$

Onde:

$\mathrm{Ge}=$ Vulnerabilidade para o tema geomorfologia;

$\mathrm{G}^{\circ}=$ Vulnerabilidade atribuída ao grau de dissecação;

$\mathrm{A}=$ Vulnerabilidade atribuída à amplitude altimétrica;

$\mathrm{D}=$ Vulnerabilidade atribuída à declividade. 
Tabela 3 - Valores atribuídos às unidades de solos, para a Bacia do Acaraú

\begin{tabular}{|c|c|c|}
\hline Unidades & Solos & Valores \\
\hline AQd2 & Neossolos quartizarênicos distróficos e latossolo amarelo distrófico & 2,0 \\
\hline Ae3 & Neossolos flúvicos eutróficos, vertissolo e planossolo nátrico & 3,0 \\
\hline LVd7 & Latossolo verm/amarelo distrófico e latossolo verm/amarelo álico & 1,0 \\
\hline $\mathrm{NC} 14$ & Luvissolo, luvissolo e neossolos litólicos eutróficos & 2,3 \\
\hline $\mathrm{NC} 15$ & Luvissolo, vertissolo e luvissolo & 2,3 \\
\hline NC7 & Luvissolo, argissolo verm/amarelo eutrófico, neossolos litólicos eutróficos e planossolo solódico & 2,3 \\
\hline PE1 & Argissolo verm/amarelo eutrófico & 2,0 \\
\hline PE12 & Argissolo verm/amarelo eutrófico e planossolo solódico & 2,0 \\
\hline PE13 & Argissoloverm/amarelo eutrófico, neossolos litólicos eutróficos e luvissolo & 2,3 \\
\hline PE14 & Argissolo verm/amarelo eutrófico e neossolos litólicos eutróficos & 2,5 \\
\hline PE22 & Argissolo verm/amarelo eutrófico, latossolo verm/amarelo distrófico e neossolos litólicos eutróficos & 2,0 \\
\hline PE27 & Argissolo verm/amarelo eutrófico, argissolo verm/amarelo eutrófico e neossolos litólicos eutróficos & 2,3 \\
\hline PE28 & Argissolo verm/amarelo eutrófico, luvissolo e neossolos litólicos eutróficos & 2,3 \\
\hline PE38 & Argissolo verm/amarelo eutrófico e neossolos litólicos eutróficos & 2,5 \\
\hline PE39 & Argissolo verm/amarelo eutrófico, argissolo verm/amarelo eutrófico e neossolos litólicos eutróficos & 2,3 \\
\hline PE5 & Argissolo verm/amarelo eutrófico e neossolos litólicos eutróficos & 2,5 \\
\hline PE8 & Argissolo verm/amarelo eutrófico, luvissolo e neossolos litólicos eutróficos & 2,3 \\
\hline PL3 & Planossolo solódico, planossolo nátrico e neossolos litólicos eutróficos & 2,5 \\
\hline PL4 & Planossolo solódico, neossolos litólicos eutróficos e planossolo nátrico & 2,5 \\
\hline PL6 & Planossolo solódico, planossolo nátrico, neossolos flúvicos eutróficos e neossolos litólicos eutróficos & 2,5 \\
\hline PV6 & Argissolo verm/amarelo distrófico e solos aluviais eutróficos & 2,5 \\
\hline PV7 & Argissolo verm/amarelo distrófico, argissolo verm/amarelo eutrófico e argissolo verm/amarelo latossólico distrófico & 2,0 \\
\hline REd2 & Neossolo regolítico distrófico e planossolo nátrico & 3,0 \\
\hline REe3 & Neossolo regolítico, planossolo nátricoe afloramento de rocha & 3,0 \\
\hline Re14 & Neossolos litólicos eutróficos e argissolo verm/amarelo eutrófico & 2,7 \\
\hline Re15 & Neossolos litólicos eutróficos e planossolo solódico & 2,7 \\
\hline $\operatorname{Re} 16$ & Neossolos litólicos eutróficos, luvissolo e solos concrecionários eutróficos & 2,5 \\
\hline $\operatorname{Re} 19$ & Neossolos litólicos eutróficos e luvissolo & 2,8 \\
\hline $\operatorname{Re} 23$ & Neossolos litólicos eutróficos, luvissolo e solonetz solodizado & 2,7 \\
\hline $\operatorname{Re} 26$ & Neossolos litólicos eutróficos, luvissoloe podzólico verm/amarelo eutrófico & 2,6 \\
\hline $\operatorname{Re} 3$ & Neossolos litólicos eutróficos e podzólico verm/amarelo distrófico & 2,5 \\
\hline $\operatorname{Re} 7$ & Neossolos litólicos eutróficos e luvissolo & 2,5 \\
\hline $\operatorname{Re} 8$ & Neossolos litólicos eutróficos, argissolo verm/amarelo distrófico e planossolo solódico & 2,6 \\
\hline Red11 & Neossolos litólicos eutróficos e distróficos, argissolo verm/amarelo eutrófico e afloramento de rocha & 2,6 \\
\hline Red4 & Neossolos litólicos eutróficos e distróficos e planossolo nátrico & 2,8 \\
\hline SK2 & Solonchak sódico, planossolo nátrico, planossolo solódico e neossolos flúvicos eutróficos & 2,8 \\
\hline
\end{tabular}

Fonte das unidades de solos: RADAMBRASIL (1973) 
Tabela 4 - Valores atribuídos às unidades de vegetação para a Bacia do Acaraú

\begin{tabular}{cc}
\hline Classes & Valores \\
\hline Caatinga Arbustiva Aberta & 3,0 \\
Caatinga Arbustiva Densa & 2,7 \\
Complexo Vegetacional da Zona Litorânea & 1,7 \\
Floresta Caducifólia Espinhosa (Caatinga Arbórea) & 1,7 \\
Floresta Mista Dicotilo-Palmaceae (Mata Ciliar com Carnaúba) & 2,0 \\
Floresta Perenifólia Paludosa Maritima & 2,5 \\
Floresta Subcaducifólia Tropical Pluvial (Mata Seca) & 1,5 \\
Floresta Subperenifólia Tropical Pluvio-Nebular (Mata úmida) & 1,2 \\
\hline
\end{tabular}
Fonte das unidades de vegetação: IPECE

Na Tabela 5 observam-se os valores de vulnerabilidade para a amplitude e altimetria referente ao tema geomorfologia.

Os valores dos graus de vulnerabilidade para a declividade foram calculados segundo a regressão apresentada na Figura 2, tendo como 3,0 o valor limite superior, e o modelo digital de elevação utilizado foi o gerado pela missão SRTM.

Tabela 5 - Valores atribuídos às unidades de relevo grau de dissecação $\left(\mathrm{G}^{\mathrm{o}}\right)$ e amplitude altimétrica (A)

\begin{tabular}{|c|c|c|c|}
\hline Abreviatura & Relevo & $\mathrm{G}^{\circ}$ & A \\
\hline a12 & Planalto da Ibiapaba & 3,0 & 1,5 \\
\hline $\mathrm{c} 11$ & Planalto sertanejo & 3,0 & 1,0 \\
\hline Aai & Áreas de acumulação inundáveis & 1,0 & 1,0 \\
\hline a11 & Depressão sertaneja & 3,0 & 1,0 \\
\hline a12 & Depressão sertaneja & 3,0 & 1,5 \\
\hline a22 & Depressão sertaneja & 2,5 & 1,5 \\
\hline$a 23$ & Depressão sertaneja & 2,5 & 2,0 \\
\hline $\mathrm{c} 11$ & Depressão sertaneja & 3,0 & 1,0 \\
\hline $\mathrm{c} 12$ & Depressão sertaneja & 3,0 & 1,5 \\
\hline $\mathrm{c} 22$ & Depressão sertaneja & 2,5 & 1,5 \\
\hline c32 & Depressão sertaneja & 2,0 & 1,5 \\
\hline $\mathrm{t} 11$ & Depressão sertaneja & 3,0 & 1,0 \\
\hline $\mathrm{t} 21$ & Depressão sertaneja & 2,5 & 1,0 \\
\hline $\mathrm{t} 32$ & Depressão sertaneja & 2,0 & 1,5 \\
\hline $\mathrm{t} 41$ & Depressão sertaneja & 1,5 & 1,0 \\
\hline $\mathrm{t} 51$ & Depressão sertaneja & 1,0 & 1,0 \\
\hline Et & Planalto da Ibiapaba & 3,0 & 1,5 \\
\hline a22 & Planalto da Ibiapaba & 2,5 & 1,5 \\
\hline a23 & Planalto da Ibiapaba & 2,5 & 2,0 \\
\hline $\mathrm{t} 12$ & Planalto da Ibiapaba & 3,0 & 1,5 \\
\hline $\mathrm{t} 22$ & Planalto da Ibiapaba & 2,5 & 1,5 \\
\hline $\mathrm{t} 31$ & Planalto da Ibiapaba & 2,0 & 1,0 \\
\hline $\mathrm{t} 52$ & Planalto da Ibiapaba & 1,0 & 1,5 \\
\hline
\end{tabular}


Continuação da Tabela 5

\begin{tabular}{cccc}
\hline Epd & Planalto residual & 2,5 & 2,5 \\
a11 & Planalto residual & 3,0 & 1,0 \\
a13 & Planalto residual & 3,0 & 2,0 \\
a23 & Planalto residual & 2,5 & 2,0 \\
a24 & Planalto residual & 2,5 & 2,5 \\
a33 & Planalto residual & 2,0 & 2,0 \\
c22 & Planalto residual & 2,5 & 1,5 \\
t11 & Planalto residual & 3,0 & 1,0 \\
Et & Planalto sertanejo & 2,5 & 1,5 \\
a22 & Planalto sertanejo & 1,5 \\
a23 & Planalto sertanejo & 2,5 & 2,0 \\
a33 & Planalto sertanejo & 2,5 & 2,0 \\
c12 & Planalto sertanejo & 2,0 & 1,5 \\
c22 & Planalto sertanejo & 3,0 & 1,5 \\
t21 & Planalto sertanejo & 2,5 & 1,0 \\
t22 & Planalto sertanejo & 2,5 & 1,5 \\
t32 & Planalto sertanejo & 2,5 & 1,5 \\
t41 & Planalto sertanejo & 2,0 & 1,0 \\
t51 & Planalto sertanejo & 1,5 & 1,0 \\
Apf & Planície fluvial & 1,0 & 1,0 \\
Apfm & Planície litorânea & 1,0 & 1,0 \\
Ep & Superficie sertaneja & 1,0 & 1,0 \\
a11 & Superficie sertaneja & 1,0 & 1,0 \\
c11 & Superficie sertaneja & 3,0 & 1,0 \\
t41 & Superficie sertaneja & 3,0 & 1,0 \\
\hline
\end{tabular}

Fonte das unidades de relevo: RADAMBRASIL (1973)

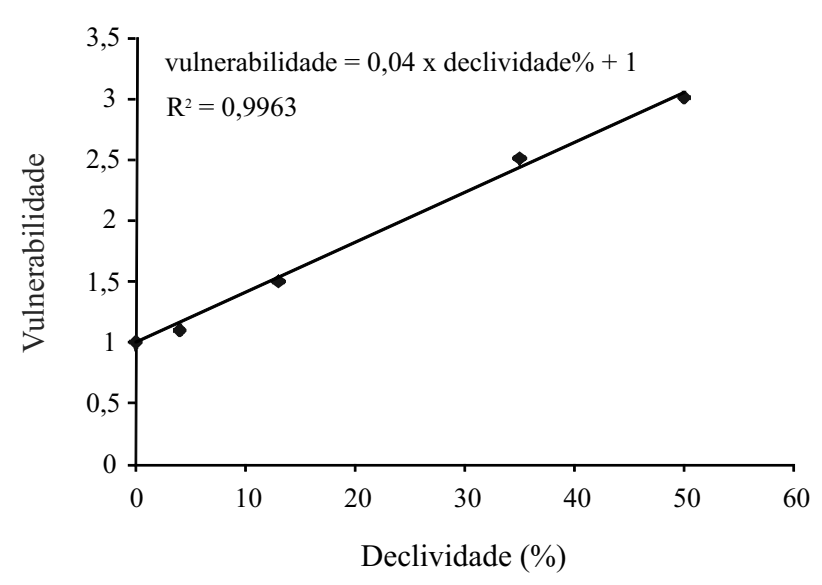

Figura 2 - Regressão entre declividade (\%) e o valor do grau de vulnerabilidade(D), adaptado de Crepani et al. (2001)
Os valores de intensidade pluviométrica para a elaboração do mapa de vulnerabilidade do clima foram obtidos a partir do Levantamento ExploratórioReconhecimento de Solos do Estado do Ceará(BRASIL, 1973). A vulnerabilidade para o tema clima apresenta os valores do grau de vulnerabilidade das unidades de mapeamento do clima (TAB. 6).

Tabela 6 - Valores atribuídos às unidades do clima

\begin{tabular}{cc}
\hline Intensidade pluviométrica (mm/ano) & Valores \\
\hline $500-750$ & 1,1 \\
$750-1000$ & 1,2 \\
\hline
\end{tabular}

Fonte das unidades de clima: IPECE 


\section{Resultados e discussão}

\section{Geologia}

A partir dos valores calculados para cada unidade litológica das principais rochas existentes na associação litológica (TAB. 2), pode-se observar maior estabilidade em relação aos processos erosivos proporcionada pela base geológica cristalina e metamórfica e a alta vulnerabilidade das áreas com depósitos sedimentares inconsolidados ou pouco consolidados.

Foi observado que, em aproximadamente $90 \%$ da área da bacia do Acaraú, predominaram rochas ígneas e metamórficas. Segundo Gomes (2005), as rochas granitóides possuem alta resistência ao intemperismo, o que as colocam como estáveis. Isso é muito observado em áreas onde o solo é pedregoso ou o granito aflora devido ao seu lento desgaste. $\mathrm{O}$ granito e o migmatito possuem valores que os caracterizam como estáveis aos processos de intemperismo, porém, o xisto possui uma maior vulnerabilidade a este processo.

Os $10 \%$ restantes da área é formado por rochas sedimentares ou sedimentos. Os sedimentos inconsolidados estão entre os mais instáveis à vulnerabilidade, pois se localizam em áreas do Grupo Barreiras e ao longo dos leitos dos rios, áreas onde uma grande quantidade de material é transportada principalmente pela água e a areia que é transportada durante os períodos onde o fluxo de água nos canais de drenagem é intenso.

O mapa de vulnerabilidade para o tema geologia é apresentado na Figura 3a.

\section{Geomorfologia}

As superfícies aplainadas são caracterizadas por relevos planos a suavemente ondulados onde os valores são considerados estáveis aos processos de perda de solo. Áreas com relevo dissecado em colinas apresentam valores intermediários, pois, apesar da dissecação, os topos aplainados ou convexos não permitem a perda de solo tão rápida quanto a que acontece em relevos dissecados em cristas. Nestas áreas, as vertentes são mais inclinadas e a água das chuvas provoca uma aceleração nos processos de perda de solo e escoamento superficial (FREITAS; CARVALHO, 2009). A planície aluvionar é a mais instável das classes, pois neste tipo de relevo ocorre a acumulação de sedimentos. Estes sedimentos, provenientes do arraste de outras áreas pela ação da água, decorrem dos processos de modificação do relevo (SIQUEIRA et al., 2006). Para a variável amplitude altimétrica, pode-se perceber que, quanto menor a amplitude altimétrica, relacionada ao ponto
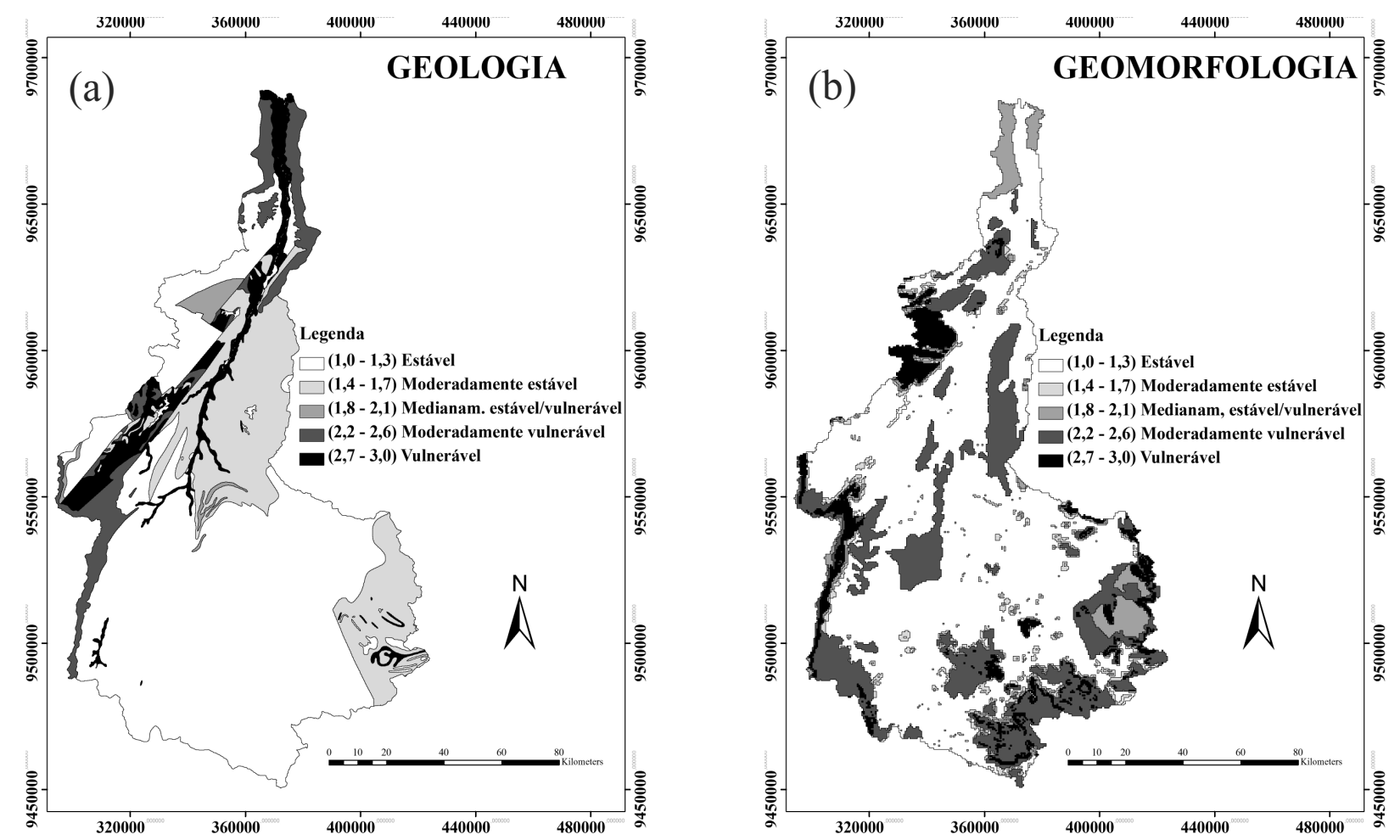

Figura 3 - Mapa de vulnerabilidade para os temas geologia (a), geomorfologia (b) 
mais alto e mais baixo de cada uma das formas de relevo, mais estável é a unidade geomorfológica. Neste caso, o relevo é mais plano e a perda de solo é mais lenta do que em relevos mais acidentados (CREPANI et al., 2001).

De uma forma geral, a geomorfologia, apresentando uma média entre os três índices morfométricos (Eq. 2), indicou que a região estudada possui extensas áreas aplainadas, com baixa amplitude interfluvial, onde a estabilidade predomina. A amplitude altimétrica predominantemente alta na área de estudo indica a presença de relevos residuais que afetam a geração da grade e, por conseguinte, sua espacialização. Os relevos residuais possuem valores diferenciados devido às características das suas vertentes que aliadas à chuva, adquirem uma alta velocidade e um alto poder de escoamento superficial (runoff).

O mapa de vulnerabilidade para o tema geomorfologia é apresentado na Figura 3b.

\section{Pedologia}

Os Latossolos são considerados solos estáveis aos processos de perda de solo, pois são bem desenvolvidos, com grande profundidade, elevada porosidade e avançado grau de intemperismo (KER, 1997; MATIAS et al., 2009). Os solos considerados com grau de vulnerabilidade medianamente estável/ vulnerável abrangem as classes dos Argissolos, Planossolos e Luvissolos (CREPANI et al., 2001). Estes solos possuem diferenças com relação aos outros solos baseadas no gradiente textural entre os horizontes A e B, dificultando a infiltração da água e favorecendo os processos de perda de solo.

Os solos vulneráveis são aqueles classificados como os Neossolos Regolíticos, Neossolos Litólicos, Vertissolos, entre outros, pois são considerados solos pouco desenvolvidos (CREPANI et al., 2001). Neles, ocorre a ausência do horizonte $\mathrm{B}$, assentando-se diretamente sobre o horizonte $\mathrm{C}$ ou sobre a rocha mãe. Apesar da rocha mãe (granitóides) ser bastante resistente aos processos de intemperismo, o solo, em particular, é bastante instável. A bacia do Acaraú apresenta em sua maior parte solos do tipo Luvissolo e Neossolos Litólicos, o que lhe confere um grau de vulnerabilidade entre moderadamente vulnerável a vulnerável.

O mapa de vulnerabilidade para o tema solos é apresentado na Figura 4a.
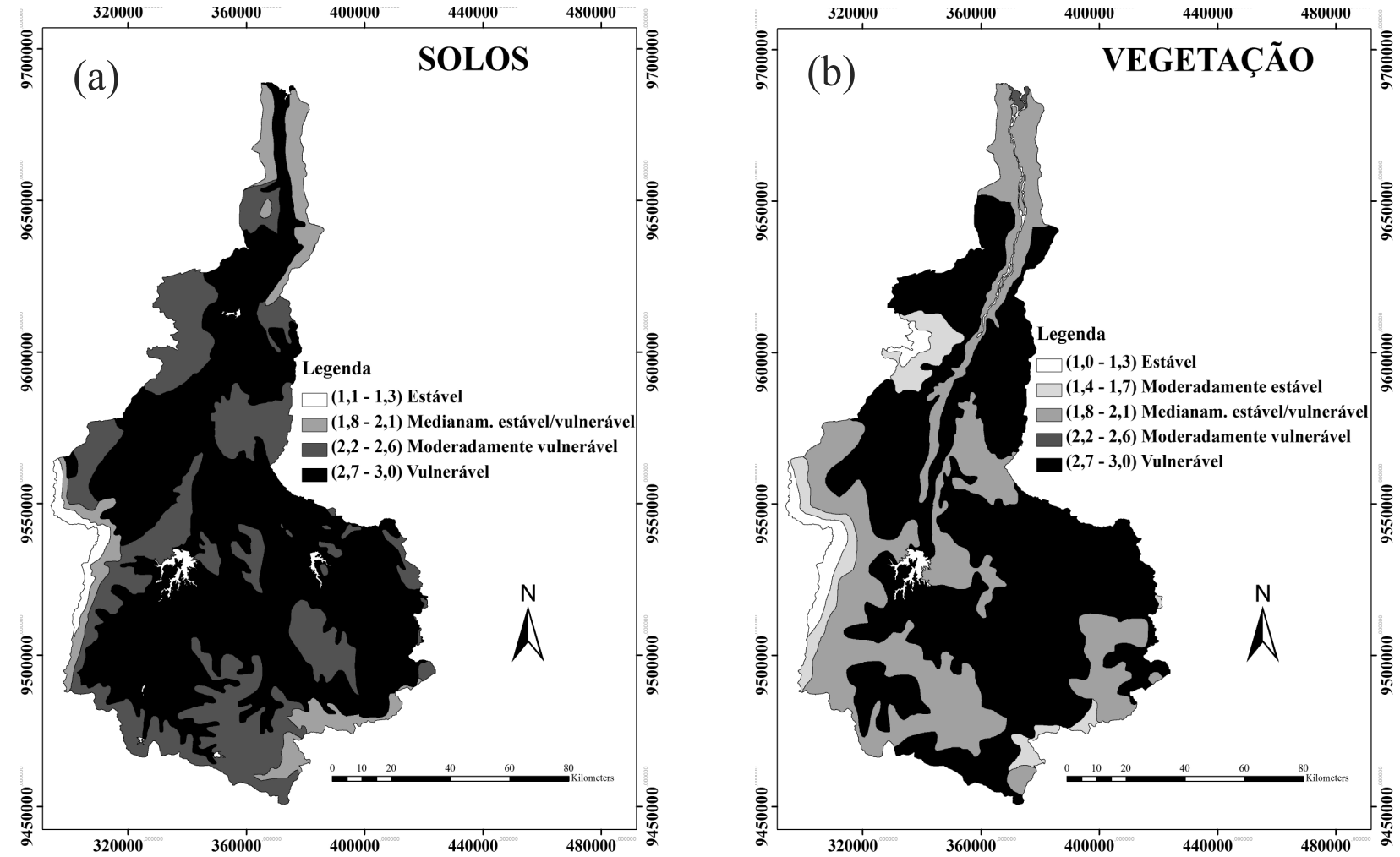

Figura 4 - Mapa de vulnerabilidade para os temas pedologia (a) e vegetação (b) 


\section{Vegetação}

A análise da perda de solo está baseada na cobertura que a vegetação e a atividade antrópica proporcionam ao solo (GOMES, 2005). Partindo desta premissa, as áreas mais estáveis seriam as ocupadas por vegetação densa e fechada, como a floresta subperenifólia. A caatinga arbustiva aberta permite uma maior penetração da água da chuva, favorecendo o maior escoamento superficial da água e consequente intensificação da erosão do solo.

A partir do mapa de vulnerabilidade para o tema vegetação (FIG. 4b), é possível observar que a Floresta Caducifólia Espinhosa (Caatinga Arbórea), juntamente com a caatinga arbustiva aberta e a caatinga arbustiva densa, são as que se apresentam em maior proporção na área, conferindo-lhe alto grau de vulnerabilidade.

\section{Clima}

A intensidade pluviométrica está ligada à erosividade das chuvas (SILVA; CORRÊA, 2007) que encontram o solo mais exposto na época seca devido à ausência de vegetação. Com isso, o impacto das gotas da chuva desagrega o solo, ocasionando enxurradas e consequente perda de solo pela erosão (BERTOL et al., 2007).

A partir do mapa de vulnerabilidade para o tema clima (FIG. 5), é possível observar que a bacia do Acaraú, por estar inserida em condições climáticas semiáridas, ficou com grau de vulnerabilidade estável, pois, de acordo com o levantamento exploratórioreconhecimento dos solos do Estado do Ceará (BRASIL, 1973), a bacia do Acaraú apresenta-se com isoieta entre 500 a $1000 \mathrm{~mm} /$ ano. Assim, como constatado em estudo realizado por Ribeiro e Campos (2007), a vulnerabilidade do solo à erosão foi pouco influenciada pela pluviosidade. Dessa forma, esse mapa não representou a real situação em relação ao clima para a referida área de estudo, pois segundo Andrade et al. (2006), as chuvas, nessa região, apresentam uma distribuição unimodal com $80 \%$ do total concentrado nos meses de fevereiro a maio.

Outro motivo que pode ser levado em consideração é que a metodologia desenvolvida por Crepani et al. (2001) foi para a Amazônia Legal, onde os volumes pluviométricos geralmente são muito maiores. Nesse caso, estes valores poderiam ser adaptados para o semiárido, resultando em uma escala maior.

\section{Vulnerabilidade à Degradação dos Solos}

No mapa de vulnerabilidade à degradação dos solos da bacia do Acaraú (FIG. 8), é possível observar

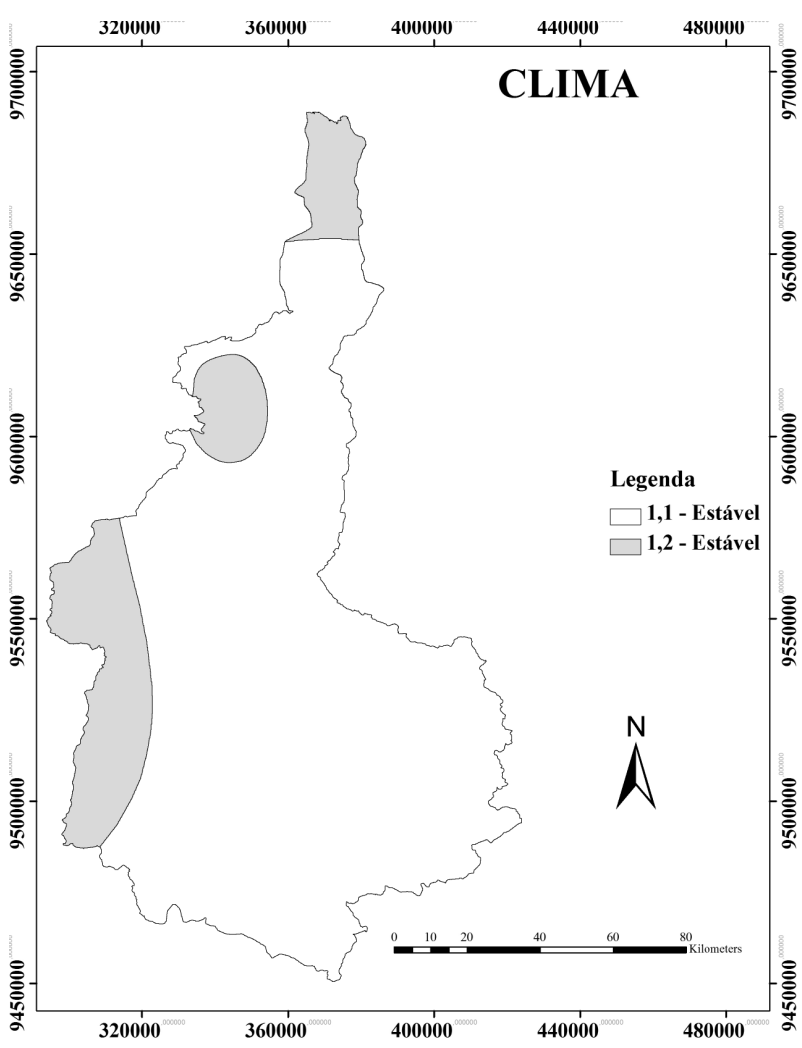

Figura 5 - Mapa de vulnerabilidade para o tema clima

que a classe considerada medianamente estável/ vulnerável predomina em $9.776 \mathrm{~km}^{2}$ de extensão, apresenta-se em mais de $67 \%$ da área, conforme é mostrado na Tabela 7.

A classe moderadamente estável apresentase em $4.180 \mathrm{~km}^{2}$ de extensão e representa mais de $28 \%$ da região estudada. Pode-se dizer que a quase totalidade da área (mais de 95\%) pertence às classes medianamente estável/vulnerável e moderadamente estável devido ao fato dessa bacia se compor de áreas com rochas resistentes ao intemperismo associada com as extensas áreas aplainadas, presença de solos das classes dos latossolos, podzólicos, planossolos e bruno não cálcicos.

Estas observações estão de acordo com os resultados apresentados por Diniz et al. (2008) que constataram que, apesar da bacia do Rio Acaraú apresentar um relevo aplainado e com baixa declividade, ocorrem processos de erosão na região.

A classe estável ocupa somente $0,3 \%$ da área de estudo e moderadamente vulnerável apenas $2,9 \%$. Não foi verificada nenhuma região na classe vulnerável. 


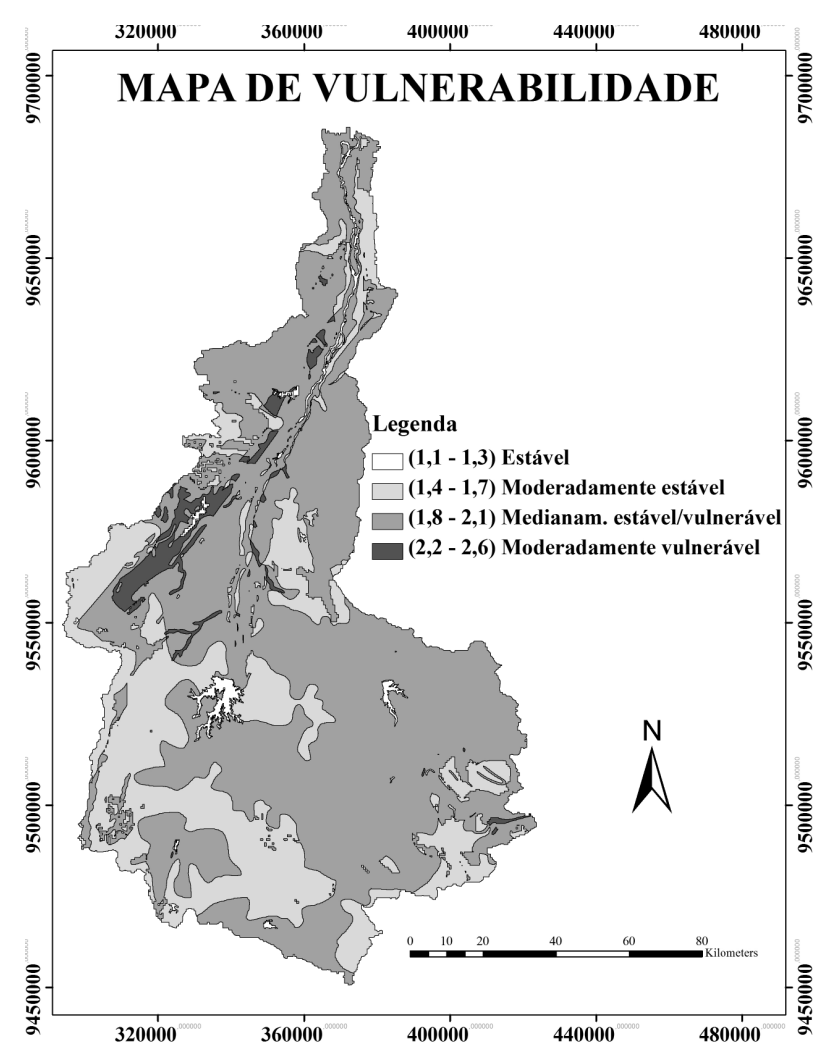

Figura 8 - Mapa de vulnerabilidade à degradação dos solos da bacia do Acaraú

Tabela 7 - Distribuição das áreas das classes de vulnerabilidade natural à degradação dos solos na bacia do rio Acaraú

\begin{tabular}{crcc}
\hline Classes & Área $\left(\mathrm{km}^{2}\right)$ & \multicolumn{1}{c}{$\%$} & Graus \\
\hline Estável & 47,80912 & 0,332 & $1,0-1,3$ \\
Moderadamente & 4179,579 & 28,993 & $1,4-1,7$ \\
$\begin{array}{c}\text { Estável } \\
\text { Medianamente } \\
\text { Estável/Vulnerável } \\
\text { Moderadamente } \\
\text { Vulnerável }\end{array}$ & 9775,528 & 67,810 & $1,8-2,1$ \\
Vulnerável & 413,0839 & 2,865 & $2,2-2,6$ \\
\hline Total & 0,0 & 0,0 & $2,7-3,0$ \\
\hline
\end{tabular}

\section{Conclusão}

O método de multicritério aditivo e o uso do SIG foram eficientes no mapeamento da vulnerabilidade à degradação dos solos da bacia do Acaraú e mostra-se como uma base sintética adequada à tomada de decisão e gestão territorial.

\section{Referências}

ANDRADE, E. M.; et al. Mapa de vulnerabilidade da bacia do Acaraú, Ceará, à qualidade das águas de irrigação, pelo emprego do GIS. Revista Ciência Agronômica, v. 37, n. 03, p. 279-286, 2006.

ARAÚJO, M. V.; FREIRE, G. S. S. Utilização de SIG nos estudos ambientais do estuário do Rio Acaraú - Ceará. Geonomos, v. 15, n. 02, p. 09-19, 2007.

BATISTA, T. M.; et al. Modelagem da estrutura iônica das águas da bacia hidrográfica do Acaraú, Ceará. Revista Ciência Agronômica, v. 37, n. 01, p. 01-06, 2006.

BATISTELLA, M.; VALLADARES, G. S. Farming expansion and land degradation in western Bahia, Brasil. Biota Neotropica, v. 09, n. 03, p. 61-76, 2009.

BERTOL, O. J.; et al. Perdas de solo e água e qualidade do escoamento superficial associadas à erosão entre sulcos em área cultivada sob semeadura direta e submetida às adubações mineral e orgânica. Revista Brasileira de Ciência do Solo, v. 31, n. 04, p. 781-792, 2007.

BRASIL. Levantamento exploratório - reconhecimento de solos do Estado do Ceará. Recife, DPP-MA/DNPEASUDENE-1973, Rv. (Boletim Técnico $\mathrm{n}^{\circ}$ 28).

COGERH. COMPANHIA DE GESTÃO DOS RECURSOS HÍDRICOS. A bacia hidrográfica do Acaraú. Fortaleza, 2009. Disponível em: <http://portal.cogerh.com.br/eixos-de-atuacao/ gestao-participativa/comites-de-bacias/comite-da-baciahidrografica-do-acarau>. Acesso em: 10 mai. 2009.

CREPANI, E.; etal.Sensoriamento remoto egeoprocessamento aplicados ao zoneamento ecológico-econômico e ao ordenamento territorial. José dos Campos, Instituto Nacional de Pesquisas Espaciais (INPE-8454-RPQ/722). 2001, 103p.

DINIZ, S. F.; et al. Susceptibilidade erosiva do baixo curso do rio Acaraú-CE. Geociências, v. 27, n. 03, p. 355-367, 2008.

FREITAS, M. W. D.; CARVALHO, V. C. Uso de geotecnologias para o mapeamento integrado de paisagens no Sertão Pernambucano (NE - Brasil). Geografia, v. 34, n. 02, p. 537-558, 2009.

GOMES, A. G. Avaliação da vulnerabilidade à perda de solo em região semi-árida utilizando sensoriamento remoto e geoprocessamento - área piloto de Parnamirim (PE). 2005. 165f. Dissertação (Mestrado em Sensoriamento Remoto) - Instituto Nacional de Pesquisas Espaciais, São José dos Campos.

KER, J. C. Latossolos do Brasil: uma revisão. Geonomos, v. 05, n. 01, p. 17-40, 1997.

KÖPPEN, W.; GEIGER, R. Klimate der Erde. Gotha: Verlag Justus Perthes. 1928. Wall-map $150 \mathrm{~cm} \times 200 \mathrm{~cm}$.

MAFRA, N. M. C. Esquema metodológico para la planificación de usos del suelo em zonas tropicales húmedas: aplicación a la Region Norte del Estado del Rio de Janeiro, Brasil. Tese (Doutorado em Edafologia) - Universitat de Valéncia. Facultat de Geografía e Historia, Valéncia, 1997. 
MATIAS, S. S. R.; et al. Atributos físicos de um Latossolo Vermelho submetido a diferentes usos. Revista Ciência Agronômica, v. 40, n. 03, p. 331-338, 2009.

MEIRELES, A. C. M.; et al. Sazonalidade da qualidade das águas do açude Edson Queiroz,

bacia do Acaraú, no Semi-Árido cearense. Revista Ciência Agronômica, v. 38, n. 01, p. 25-31, 2007.

MELLO, G.; et al. Variabilidade espacial de perdas de solo, do potencial natural e risco de erosão em áreas intensamente cultivadas. Revista Brasileira de Engenharia Agrícola e Ambiental, v. 10, n. 02, p. 315-322, 2006.

NASCIMENTO, F. R.; et al. Diagnóstico geoambiental da bacia hidrográfica semi-árida do Rio Acaraú: subsídios aos estudos sobre desertificação. Boletim Goiano de Geografia, v. 28 , n. 1, p. 41-62, 2008.

NASCIMENTO, W. M.; VILLAÇA, M. G. Bacias hidrográficas: planejamento e gerenciamento. Revista Eletrônica da Associação dos Geógrafos Brasileiros - Seção Três Lagoas, v. 01, n. 07, p. 102-120, 2008.

NASA. NATIONAL AERONAUTICS AND SPACE ADMINISTRATION. The Shuttle Radar Topography Mission: The Mission to Map the World. Fortaleza, 2009. Disponível em: <http://www2.jpl.nasa.gov/srtm/index.html>. Acesso em: 25 ago. 2009.

NAVAS, A.; et al. Assessing soil erosion in a Pyrenean mountain catchment using GIS and fallout ${ }^{137} \mathrm{Cs}$. Agriculture, Ecosystems and Environment, v. 105, n. 03, p. 493-506, 2005.

RADAMBRASIL, Projeto. Folhas SA-24 Fortaleza e SB-24 Jaguaribe. Geologia, geomorfologia, solos, vegetação e uso potencial da terra. Rio de Janeiro. 1973. (Levantamento de Recursos Naturais, 2 e 3).

RIBEIRO, F. L.; CAMPOS, S. Vulnerabilidade à erosão do solo da região do Alto Rio Pardo, Pardinho, SP. Revista Brasileira de Engenharia Agrícola e Ambiental, v. 11, n. 06, p. 628-636, 2007.

SILVA, F. L. M.; CORRÊA, A. C. B. Relações entre geossistemas e usos da terra em microbacia hidrográfica semi-árida: o caso do riacho Gravatá/Pesqueira - PE. Revista de Geografia, v. 24, n. 01, 2007.

SIQUEIRA, M. R. A.; et al. Mapeamento das áreas de inundações das planícies aluviais de Guaratinguetá através de técnicas de geoprocessamento. In: SEMINÁRIO DE GEOPROCESSAMENTO DO VALE DO PARAÍBA, 1., 2006, Taubaté. Anais... Taubaté: UNITAU. 1 CD.

SOBRINHO, J. F. A compartimentação geomorfológica do Vale do Acaraú: distribuição das águas e pequeno agricultor. Mercator - Revista de Geografia da UFC, ano 05, n. 10, p. 91-110, 2006.

SPÖRL, C.; ROSS, J. L. S. Análise comparativa da fragilidade ambiental com aplicação de três modelos. GEOUSP - Espaço e Tempo, n. 15, p. 39-49, 2004.

SUCUPIRA, P. A. P. Indicadores de degradação ambiental dos recursos hídricos superficiais no Médio e Baixo Vale do Rio Acaraú - CE. 2006. 242 f. Dissertação (Mestrado) Universidade Federal do Ceará, Fortaleza.

TRICART, J. Ecodinâmica. Rio de Janeiro, FIBGE/SUPREN. 1977. 91p.

VALLADARES, G. S.; FARIAS, A. L. L. SIG na análise do risco de salinização na bacia do Rio Coruripe, AL. Engevista, v. 06, n. 03, p. 86-98, 2004. 